\title{
JUURNAL_RU
}

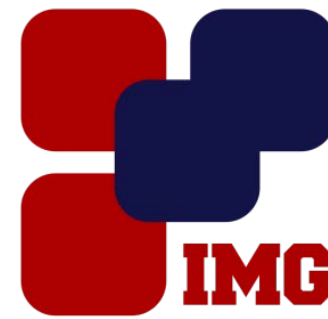

Iyanoy
MaNagement
GRoup

Плетенёва И.Ф., Баринова Л.В. Елеикий Государственный Университет им. И.А. Бунина

Елеи, Россия

Муниципальное бюджетное общеобразовательное учреждение средняя общеобразовательная школа №21 г. Липецка

Липецк, Россия

doi: 10.18411/lj-30-11-2016-4-09

idsp 000001:lj-30-11-2016-4-09

\section{Реализация опыта взаимодействия семьи и школы в современной воспитательной практике}

\section{Аннотация.}

В статье рассматриваются формы взаимодействия семьи и школыво всестороннем развитии подрастающего поколения. Повышение качества воспитания и образования учащихся - основа взаимодействия семьи и школы на современном этапе.Представлен анализ историко-педагогических идей и приемов взаимодействия семьи и школы в XIX и XXI вв.Обращение к истории, изучение исторического опыта позволяют сделать вывод, что в настоящее время педагоги используют основные формы и методы взаимодействия семьи и школы, апробированные в XIX в.

Ключевые слова: Взаимодействие, воспитание, образование, развитие,родители, семья, сотрудничество, школа.

Современный период в российской истории образования - время смены ценностных ориентиров. В этот период нарушается «духовное единство общества, меняются жизненные приоритеты молодежи, происходит разрушение ценностей старшего поколения, а также деформация традиционных для страны моральных и нравственных установок» [5].

Поэтому одной из приоритетных задач государства и важнейшей целью современного образования является воспитание всесторонне развитого, инициативного и компетентного гражданина России. Решение данной задачи представляет собой важный компонент социального заказа для образования.

Развитие и воспитание гражданина России является ключевым фактором развития страны, обеспечения политической и экономической стабильности. 
Важнейшие документы, принятые в настоящее время, направлены на решение данной задачи и определяют стратегию развития российского образования на ближайшие годы. Примером служит Федеральный закон «Об образовании в РФ», принятый в 2012 г., в котором одним из основных принципов государственной политики в образовании определено «... свободное развитие личности, воспитание взаимоуважения, трудолюбия, гражданственности, патриотизма, ответственности, правовой культуры, бережного отношения к природе и окружающей среде...» (Ст.3.п.3) [11]. Другими словами, взят курс на всестороннее развитие подрастающего поколения.

Понятие «всестороннее развитие» подразумевает множество путей воспитания, среди них: умственное, нравственное, патриотическое, правовое, трудовое, физическое, эстетическое, экологическое и т.д.

Несомненно, самым главным вопросом остается вопрос духовнонравственного развития подрастающего поколения. В выступлениях ученых, педагогов, общественных и религиозных деятелей всё чаще звучит вопрос о кризисе в духовно - нравственном воспитании молодежи.О духовном неблагополучии молодежи говорят следующие факты: рост табачной, алкогольной, наркотической и компьютерной зависимостей; увеличение числа уходов детей из дома, беспризорность и бродяжничество, что привело к росту детской и подростковой преступности и др.

В связи с перечисленными негативными явлениями духовно-нравственное воспитание молодого поколения приобретает наивысшую значимость, т.е. становится приоритетной государственной задачей. Ответственность за осуществление процесса духовно - нравственного воспитания детей ложится, прежде всего, на семью и школу. Подтверждением тому служит принятие Концепции духовно-нравственного развития и воспитания личности гражданина России, где указано, что «процесс образования связан с развитием личности, принятием духовно-нравственных, социальных, семейных» и других ценностей [2].

Не менее актуален вопрос патриотического воспитания молодежи, о чём свидетельствует пристальное внимание Президента России. В своём выступлении В.В. Путин подчеркнул, что «проблема патриотического воспитанияназрела давно, на самом деле это разговор о самом главном: о ценностях, о нравственных основах, на которых мы можем и должны строить нашу жизнь, воспитывать детей, развивать общество, в конечном итоге укреплять нашу страну».

Решение данной задачи, по мнению В.В. Путина, лежит на плечах образовательных учреждений. Поэтому важнейший приоритет государства и общества заключается в создании условий для качественного образования, возрождения ценности знаний.

«Говоря о патриотизме, это "не просто красивые слова", а "уважение к своей истории и традициям, к духовным ценностям наших народов, нашей 
тысячелетней культуре и уникальному опыту сосуществования сотен народов и языков на территории России. Это - ответственность за свою страну и ее будущее". А для этого стране сегодня "нужны действительно живые формы работы по воспитанию патриотизма и гражданственности, а значит, опирающиеся на общественную инициативу, на служение традиционных религий, на деятельность молодёжных и военно-патриотических организаций, исторических и краеведческих клубов, других подобных структур», - считает Президент России В.В. Путин.[8].

Несомненно, решить вопросы патриотического и духовно-нравственного воспитания нельзя без решения вопроса воспитания здорового поколения. Здесь уместно напомнить словаЖ. Ж. Руссо: «Чтобы сделать ребёнка умным и рассудительным сделайте его крепким и здоровым».

Здоровье подрастающего поколения является неотъемлемой составной частью общечеловеческих ценностей любого государства.Поэтому вопрос воспитания здорового поколения также находится в зоне внимания государства. Созданы различные программы по формированию здорового образа жизни у подрастающего поколения. На уровне государства применяются меры по ограничению потребления населением алкоголя и табака, открываются спортивные и физкультурные центры, школы, площадки, клубы, создаются условия для массовых занятий физкультурой и спортом, вводятся нормы ГТО.

Воспитание здорового образа жизни является длительным педагогическим процессом, осуществляемым учителями, совместно с родителями и врачом.

Следовательно, решить вопрос духовно-нравственного и патриотического воспитания, всесторонне развитого и здорового молодого поколения невозможно без объединения усилий семьи и школы.

Особое внимание вопросу взаимодействия уделено в Концепции духовнонравственного развития и воспитания личности гражданина России, которая «представляет собой ценностно-нормативную основу взаимодействия общеобразовательных учреждений с другими субъектами социализации семьёй, общественными организациями...» [5].

Таким образом, вопрос взаимодействия семьи и школы является одним из важных вопросов модернизации системы российского образования.

Целью взаимодействия, является совместное обеспечение условий для всестороннего развития и воспитания обучающихся. Именно школа должна обеспечить условия для взаимодействия, так как школа - единственный социальный институт, через который проходят все граждане России, индикатор морально-нравственного состояния общества и государства.

Для достижения цели необходимо в «полной мере учитывать преемственность современного воспитательного идеала по отношению к национальным воспитательным идеалам прошлых эпох», обозначено в Концепции [5]. Следовательно, изучение истории отечественного образования, выстраивание процесса взаимодействия семьи и школы необходимы в 
настоящее время. Тем более, что российская система образования имеет богатый исторический опыт.

Мы провели анализ историко-педагогических идей и приемов взаимодействия семьи и школы в XIX и XXI вв.

Обращает на себя внимание тот факт, что в школьной практике именно в XIX в. начинает реализовываться сотрудничество педагогов и родителей. Для педагогики XIX в. это было весьма новым веянием. Можно сказать, XIX в. положил начало такому сотрудничеству.

Именно в XIX в. отмечено наличие в отечественных частных учебных заведениях определенного опыта сотрудничества родителей и учителей. В этих школах воспитатели и родители часто являлись единомышленниками, благодаря чему в таких школах создавалась дружеская семейная атмосфера сотрудничества. Родители оказывали школе не только финансовую поддержку, но и присутствовали на экзаменах, проводили беседы с малоуспевающими и недисциплинированными учениками, посещали школьные праздники и вечера, участвовали в оборудовании классов и кабинетов и др. [1; 6; 13].Чтобы добиться успеха в деле воспитании и образования учащихся, педагоги стали привлекать родителей к учебно-воспитательному процессу (родительские комитеты, участие в заседаниях педагогических советов и т.п.).

Во второй половине XIX в. зародились и применялись на практике следующие формы взаимодействия: лекция; конференция, день открытых дверей; открытый урок; информирование; просвещение и обучение родителей; консультирование; родительские собрания; совет; индивидуальная беседа, которая осуществлялась в основном при посещении семей учащихся, приглашение родителей в школу и прочие.

Широкое распространение, в рассматриваемый нами период, получают характеристики учащихся, которые составляются и обсуждаются на заседаниях педагогических советов и совещаниях при директоре. Основной целью является коррекция педагогических действийв процессе обучения и воспитания ученика [1; 3; 9; 12; 13]. При необходимости характеристики зачитывались родителям с целью оказания им содействия в воспитании ребенка.

Необходимо отметить, что в течение всего XIX в. осуществлялась работа по сближению семьи и школы, привлечению родителей к воспитанию и осуществлению контроля за успеваемостью и поведением детей. В результате, взаимодействие утвердилось по следующим направлениям: вовлечение родителей в учебно-воспитательный процесс и участие родителей в управлении школы, педагогическое просвещение родителей, установление доверительных отношений между педагогами и родителями, содействие педагогам в осуществлении контроля за поведением и успеваемостью ребенка со стороны родителей, постоянного внимания за его развитием.

Подобные формы и методы взаимодействия семьи и школы можно отметить в настоящее время. Зародившись в XIX в., получив своё развитие в XX в., все вышеперечисленные формы и методы взаимодействия семьи и школы 
широко применяются в настоящее время. Конечно же, они претерпели изменения, трансформировались с учетом нынешних реалий, но, по сути, содержанию мы используем те же основные формы и методы взаимодействия семьи и школы.

К примеру, информирование родителей в XIX в. осуществлялось с помощью записок, индивидуальных бесед, личных встреч и т.д. В настоящее время передать необходимую информацию педагоги могут с помощью мобильной связи, рассылки СМС, интернет ресурсов (сайт школы, электронные дневники и журналы, видео-конференции и пр.).

В отличие от гимназий XIX в. современные образовательные учреждения активно привлекают родителей к управлению школой. Более того в ФЗ «Об образовании в РФ» обозначено, что родители (законные представители) имеют право «принимать участие в управлении организацией, осуществляющей образовательную деятельность, в форме, определяемой уставом этой организации» (Ст.44 п.7) [11]. Формы участия родителей в управлении различны: Управляющий совет, Попечительский совет и др., в которых круг полномочий родителей весьма расширен: родители получили право выбора учебного плана, календарного графика, участия в распределении материальных средств и т.д.

Рассмотрим ещё один метод - метод портфолио. Это ещё один метод взаимодействия школы и семьи, основанный на сотрудничестве учителяученика-родителя.

Педагоги гимназий XIX в. были заинтересованы не только в успеваемости своих воспитанников, но и в воспитании в них самостоятельности, нравственности, т.е. всесторонне развитого подрастающего поколения. В отслеживании личностного роста учеников педагогам помогали подробные характеристики, по которым возможно было судить об успехах или неудачах воспитанника, его увлечениях и пр.

Ярким примером служит исследование школьных традиций в гимназии К.И. Мая. Основной целью воспитания К.И. Май считал гармоничное развитие всех сил и природных данных человека (прообраз основных направлений программы ФГОС второго поколения, в том числе портфолио) [1, с. 43]. Особый интерес вызывает тот факт, что оценки ученикам выставлялись только за четверти, и то только для того, чтобы выдать им итоговые документы или документы для перехода в другую школу. Взамен текущих отметок применялись характеристики, в которых по специально разработанной форме, отмечался личностный рост воспитанника (составляющие портфолио) [1, с. 46].

Мы считаем, что эти попытки осуществления сотрудничества, являются первым шагом введения в школьную практику прообраза современного портфолио и ещё одной из форм взаимодействия школы с родителями. Составление учителем характеристики и отзыва на успеваемость, поведение, внешкольную и внеурочную деятельность ученика, сбор сведений о дополнительных занятиях и достижениях, постоянная связь с родителями и 
информирование их обо всех успехах и неудачах ребенка - всё это составляющие портфолио XXI века, которые уже имели место в практике образовательных учреждений XIX в.

Таким образом, современные образовательные учреждения используют бесценный опыт взаимодействия семьи и школы в вопросе всестороннего развития учащихся, накопленный гимназиями XIX в. Освоив и опробовав основные формы и методы взаимодействия семьи и школы, педагоги XIX в. внесли неоценимый вклад в систему отечественного образования и воспитания.

Таким образом, за столь длительный период мало инноваций пришло в содержание форм и методов взаимодействия семьи и школы. Остаются традиционными такие формы, как: проведение родительских собраний, встреч с родителями, организация конференций, посещение родителей педагогами на дому, участие родителей в управлении школой в родительских комитетах, Управляющих и Попечительских советах, Ассамблеях родительской общественности, в школьных праздниках, совместно организованных вечерах, экскурсиях. Родители участвуют в формировании образовательной политики школы, привлекаются к организации оздоровительной работы, реализации культурно-досуговых программ; при психолого-педагогической целесообразности родители присутствуют на уроках и внеурочных занятиях.

Одним из условий успешного взаимодействия школы и семьи является информирование родителей о деятельности образовательного учреждения. Основные способы и формы предъявления информации следующие: публикации и объявления в средствах массовой информации; проведение Дня открытых дверей; выступления на общешкольных и классных родительских собраниях; индивидуальные консультации; листовки; папка для родителей, содержащая необходимую информацию; информационный стенд; благодарственные письма родителям, интернет-ресурсы и т.д.

К тому же, по мнению Т. Симаковой, родители придают существенное значение имиджу учреждения, результатам участия детей и педагогов во всевозможных конкурсах, выставках, предметных олимпиадах. Информация о достижениях должна всегда быть доступной и открытой для родителей. Поэтому такая форма как тематические конференции, презентации опыта семейного воспитания в средствах массовой информации и на сайтах образовательных учреждений вызывают определенный интерес, привлекают внимание родительской и педагогической общественности, деятелей науки и культуры, представителей общественных организаций [10].

Не менее важное значение в сотрудничестве семьи и школы имеют такие формы взаимодействия как индивидуальная педагогическая беседа, составление программы индивидуального развития ребенка и система совместных педагогических действий, приглашение родителей в школу, педагогическая консультация, индивидуальное педагогическое поручение, переписка и телефонные переговоры, посещение семьи ученика педагогами. 
На практике, чаще всего, когда возникает необходимость в общении и встрече, учитель приглашает родителей в школу. Данная форма работы с родителями помогает педагогам проводить индивидуальные консультации, педагогическое просвещение, вовлекать родителей в активную педагогическую деятельность. [4].

С принятием законов, направленных на модернизацию образования, современная школа становится более открытой и демократичной, что, несомненно, служит предпосылкой для организации взаимодействия образовательного учреждения и семьи. Для эффективного взаимодействия школы и семьи педагогам необходимо учитывать потребности и возможности родителей, а во взаимодействии использовать разнообразные формы работы педагога с родителями учащихся. И тогда взаимодействие принесет свои положительные результаты, усилия всех субъектов образовательных отношений принесут свои плоды во всестороннем развитии учащихся.

В Профессиональном стандарте педагога, вступающего в силу в 2017 г., роль педагога определена как ключевая в вопросах воспитания ребенка, уделяется важное место умению педагога поддерживать конструктивные воспитательные усилия родителей учащихся и привлекать семью к решению вопросов воспитания ребенка (ч.4.2, п. 14.) [7]. Поэтому основой взаимодействия семьи и школы должно быть повышение качества воспитания и образования учащихся.

Анализ данных, полученных в ходе исследования, позволил сделать вывод, что в настоящее время педагоги используют основные формы и методы взаимодействия семьи и школы, апробированные в XIX в. Конечно же, формы и методы взаимодействия получили своё развитие, они трансформировались, приобрели новые качества, содержание.

Поэтому мы считаем, что обращение к истории не поведёт к каким-то устаревшим технологиям, напротив, обращение к истории, изучение исторического опыта позволяют нам сегодня показать современному педагогу, что сейчас, в век современных технологий, необходимо расширять свой кругозор, педагогу необходимы глубокие разносторонние знания.

Именно в истории мы находим те образцы, которые показывают нам, что педагоги были достаточно начитанными и высокообразованными. Более того, архивные материалы свидетельствуют, что педагоги, действительно, были люди широкого кругозора и глубоких знаний.

Мы считаем, что в истории накоплен большой объем знаний и опыта в вопросе взаимодействия, но современный педагог пользуется только теми методическими пособиями и материалами, которые направлены непосредственно на его профессиональную деятельность. А расширить свой кругозор, повысить уровень знаний большинство педагогов не могут по разным причинам: нехватка времени, нежелание, профессиональное выгорание и т.п.

Подчеркнём, работая с архивными материалами по педагогам XIX в., мы заметили, что в тот период времени была совсем другая ситуация. 
Поэтому, мы считаем, что на сегодняшний день необходимо срочно менять ситуацию, поскольку только осознания педагогом необходимости взаимодействия с родителями недостаточно. Педагог должен знать содержание работы. Более того, он должен быть новатором в этом направлении. А для этого он должен как можно больше читать и находить для себя много новой необходимой информации в художественной и исторической литературе, в любом другом пособии. Подтверждение тому мы находим в Профессиональном стандарте педагога: «В стремительно меняющемся открытом мире главным профессиональным качеством, которое педагог должен постоянно демонстрировать своим ученикам, становится умение учиться. Готовность к переменам, мобильность, способность к нестандартным трудовым действиям, ответственность и самостоятельность в принятии решений - все эти характеристики деятельности успешного профессионала в полной мере относятся и к педагогу. Обретение этих ценных качеств невозможно без расширения пространства педагогического творчества...» [7]. 


\section{Литература}

1. Гаврилин, А. «Майские жуки»: сохранение и развитие школьных традиций в гимназии Карла Ивановича Мая. [Текст] / А. Гаврилин // Воспитание школьников. - 2001.- №2 - - С.43-47.

2. Духовно-нравственное развитие и воспитание школьников: учебнометодическое пособие. [Текст] / под общ.ред. М.А. Захарченко. - Спб.: СПб АППО, 2011.

3. Егорова, М.В. Повседневная жизнь учащихся и учителей Урала в XIX начале XX в. [Текст] / М.В. Егорова. - М.: Памятники исторической мысли, 2008.- 216 с.

4. Ильясова, А.Б. Из опыта сотрудничества школы с родителями [Текст] / А.Б. Ильясова, В.Г. Богин // Начальная школа: плюс-минус. - 2001. - №3. C. 3-8.

5. Концепция духовно-нравственного развития и воспитания личности гражданина России. [Текст]. [Электронный ресурс]. - Режим доступа:http://mosmetod.ru/metodicheskoe-prostranstvo/nachalnayashkola/inklyuzivnoe-obrazovanie/fgos/kontseptsiya-dukhovno-nravstvennogorazvitiya-i-vospitaniya-lichnosti-grazhdanina-rossii.html.

6. Лебедев, П.А. Антология педагогической мысли России второй половины XIX - начала ХХв. [Текст]/ П.А. Лебедев. - М.: Педагогика, 1990.-608c.

7. Профессиональный стандарт педагога [Электронный ресурс]:- Режим доступа: http://sovet-edu.ru/documents/.

8. Путин В.В. о патриотическом воспитании. [Электронный ресурс]:- Режим доступа:http://pandia.ru/text/79/186/8766.php.

9. Равкин, 3.И. Педагогика Царскосельского Лицея Пушкинской поры (18111812гг.): Историко-педагогический очерк. [Текст] / 3.И. Равкин. - М.: Московский психолого-социальный институт: Флинта, 1999.- 152 с.

10. Симакова, Т. Современная семья и образование: на пути к партнёрству [Текст] / Т. Симакова // Народное образование. - 2009. - №9. - С.214-219.

11. Федеральный закон от 29.12.2012 N 273-Ф3 (редакция от 23.07.2013) "Об образовании в Российской Федерации" [Электронный ресурс]: - Режим доступа:http://sudact.ru/law/doc.

12. Холодный, Г.М. Историческая записка Тамбовской гимназии. 1786-1886. [Текст]/ Г.М. Холодный.-Тамбов: Типо-литография Д.С. Семенова, 1887.$328 \mathrm{c}$.

13. Шарапова, Е.Л. Л.И. Поливанов и его гимназия. [Текст] / Е.Л. Шарапова // Педагогика. - 2000. - №8 - С.79 - 84. 